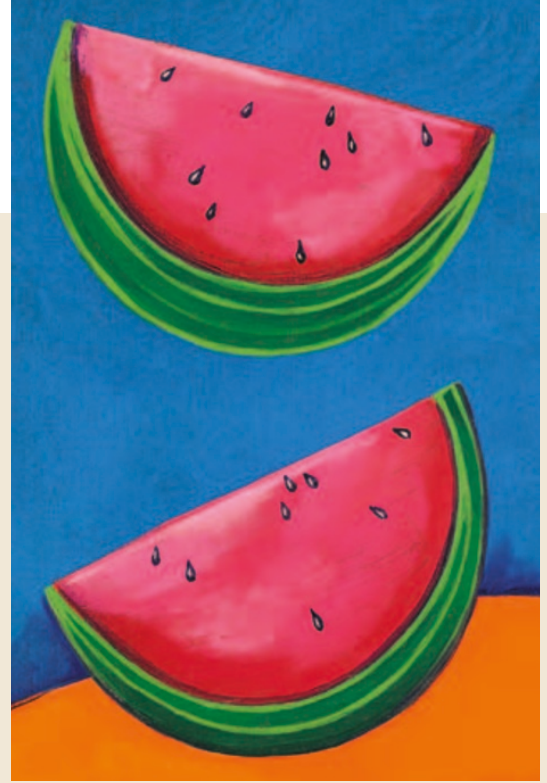
bacteria corrects these defects. However, the molecular basis for this has remained elusive. Now, data published in Cell show that the polysaccharide PSA from Bacteroides fragilis can direct the cellular and structural maturation of the mouse immune system.

Kasper and colleagues showed that colonization of the gut of germ-free mice with B. fragilis - a commensal microorganism that is abundant in 'conventional' mice (which have normal gut microflora) - was sufficient to restore both the number of $\mathrm{CD} 4^{+} \mathrm{T}$ cells in the spleen and the architecture of the spleen to those observed in conventional mice. An immunodominant surface polysaccharide of $B$. fragilis - PSA - had previously been shown to polyclonally activate $\mathrm{CD}^{+}$ $\mathrm{T}$ cells through their T-cell receptor, after internalization by dendritic cells (DCs) and presentation in the context of MHC class II molecules. In this study, colonization of germfree mice with mutant $B$. fragilis that could not express PSA did not correct the immune defects. Consistent with this, germ-free mice that were given purified PSA alone developed normal splenic $\mathrm{CD} 4^{+} \mathrm{T}$-cell numbers and splenic organization.

This is the first report that a specific bacterial product is important for In addition to activating $\mathrm{CD} 4^{+} \mathrm{T}$ cells, PSA was shown to stimulate DCs directly to produce the $\mathrm{T}$ helper $1\left(\mathrm{~T}_{\mathrm{H}} 1\right)$-cell-promoting mammalian immune-system development. cytokine interleukin-12. Accordingly, colonization with wild-type $B$. fragilis also altered the typically $\mathrm{T}_{\mathrm{H}} 2$-cytokine-skewed phenotype of germ-free mice to restore a $\mathrm{T}_{\mathrm{H}} 1 / \mathrm{T}_{\mathrm{H}} 2$-cytokine balance similar to that of conventional mice.

Davina Dadley-Moore

(1)) References and links

ORIGINAL RESEARCH PAPER Mazmanian, S. K., Liu, C. H., Tzianabos, A. O. \& Kasper, D. L. An immunomodulatory molecule of symbiotic bacteria directs maturation of the host immune system. Cel/ 122, 107-118 (2005)

\title{
NK cells need a license to kill
}

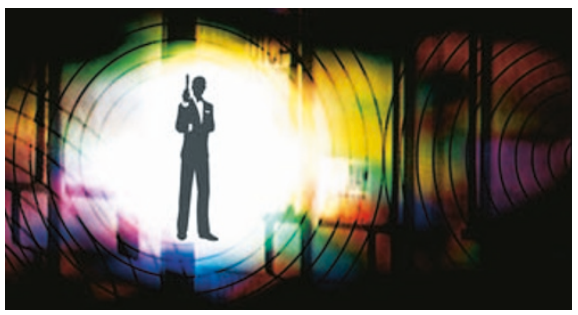

The issue of how tolerance to self is achieved in natural killer (NK) cells is a complex one. Now, Wayne Yokoyama's group have shown that NK cells are 'licensed' for functional competence by interactions between an inhibitory NK-cell receptor and a self MHC class I molecule.

The authors used a target-cell-free system to assess the function of individual NK cells by crosslinking the activating receptor NK1.1. Large numbers of NK cells from wild-type mice produced cytoplasmic interferon- $\gamma$ (IFN- $\gamma$ ), but few NK cells from mice deficient in MHC class I molecules could do so. This NK-cellintrinsic defect indicated that interaction with host MHC class I molecules is important for the functional maturation of NK cells, a process that the authors term licensing.
By investigating the role of various LY49 molecules at the surface of NK cells from hosts with different MHC haplotypes, the authors found that, paradoxically, the ability of NK cells to produce cytokines and lyse target cells depends on the expression of self-MHCclass-I-specific, inhibitory NK-cell receptors belonging to the LY49 family. To examine this in more detail, the authors generated a transgenic mouse using a single-chain trimer consisting of a peptide, $\beta_{2}$-microglobulin and the $\mathrm{H} 2-\mathrm{K}^{\mathrm{b}}$ heavy chain, which binds only LY49C. These mice were backcrossed to gene-knockout mice to produce mice that did not express any $\mathrm{MHC}$ class I molecules except $\mathrm{H} 2-\mathrm{K}^{\mathrm{b}}$. In these mice, the expression of $\mathrm{H} 2-\mathrm{K}^{\mathrm{b}}$ alone was sufficient to license $\mathrm{LY}_{49 \mathrm{C}^{+}} \mathrm{NK}$ cells for IFN- $\gamma$ production, whereas $\mathrm{LY}_{49 \mathrm{~A}^{+}} \mathrm{NK}$ cells were not licensed by $\mathrm{H} 2-\mathrm{K}^{\mathrm{b}}$.

Next, the authors used a bicistronic vector containing green fluorescent protein (GFP) and LY49A - which binds a different MHC class I molecule than does LY49C - to transduce haematopoietic stem cells. GFP ${ }^{+} \mathrm{NK}$ cells produced twofold more IFN- $\gamma$ than GFP- NK cells, showing that transduced LY49A expression conferred a positive effect on NK-cell function in hosts that express its cognate MHC class I molecule. Expression of LY49A molecules lacking a cytoplasmic domain or lacking the immunoreceptor tyrosine-based inhibitory motif (ITIM) was unable to increase NK-cell activity, showing that LY49A can directly confer the licensing signal on NK cells through the ITIM. However, examination of NK cells from mice lacking SHP1 (SRC-homology-2-domain-containing protein tyrosine phosphatase 1), which binds the ITIM that mediates inhibitory signalling, showed that licensing is distinct from the ITIM-mediated inhibition by SHP1 in effector responses.

So, this study defines a mechanism for NK-cell tolerance: NK cells that express a self-MHC-class-I-specific inhibitory receptor become licensed for functional competence, whereas those lacking such a receptor do not become licensed and are functionally inert. Licensing resembles the positive selection of $\mathrm{T}$ cells in the thymus but is distinct in that it requires the engagement of a self-MHC-specific, germline-encoded receptor that has inhibitory function in the effector response, indicating that other germline-encoded, ITIM-containing receptors might have roles in the development of other leukocytes.

Elaine Bell

(2) References and links ORIGINAL RESEARCH PAPER Kim, S. et al. Licensing of natural killer cells by host major histocompatibility complex class I molecules. Nature 436, 709-713 (2005) 